\title{
MiR-223 regulates autophagy associated with cisplatin resistance by targeting FBXW7 in human non-small cell lung cancer
}

Hui Wang ${ }^{1 \dagger}$, Jiabin Chen ${ }^{2 \dagger}$, Shufen Zhang ${ }^{2}$, Xiaoxiao Zheng ${ }^{2}$, Shangzhi Xie², Jiayan Mao ${ }^{2}$, Ying Cai ${ }^{2}$, Xuemei Lu², Liqiang $\mathrm{Hu}^{2}$, Jian Shen ${ }^{2}$, Kequn Chai ${ }^{2^{*}}$ and Wei Chen ${ }^{2^{*}}$ (D)

\begin{abstract}
Background: Cisplatin is widely used as a first-line treatment for non-small cell lung cancer (NSCLC), but chemoresistance remains a major clinical obstacle for efficient use. As a microRNA, miR-223 was reported to promote the doxorubicin resistance of NSCLC. However, whether miR-223 is also involved in cisplatin resistance of NSCLC and the mechanism miR-223 involved in drug resistance is unclear. Accumulated evidence has shown that abnormal autophagy is associated with tumor chemoresistance. The study aimed to study the role of miR-223 on cisplatin sensitivity in NSCLC and uncover the potential mechanisms.
\end{abstract}

Methods: NSCLC cells transfected with mimic or inhibitor for miR-223 was assayed for chemoresistance in vitro. MiR223 expression was assessed by quantitative real-time PCR (qRT-PCR). Western blot were used to study the expression level of F-box/WD repeat-containing protein 7 (FBXW7) and autophagy-related protein. The effect of miR-223 on cisplatin sensitivity was examined by using CCK-8, EdU assays and Autophagic flux assay. Luciferase assays, EdU assays and small interfering RNA were performed to identify the targets of miR-223 and the mechanism by which it promotes treatment resistance. Xenograft models were established to investigate the effect of mir-223 on cisplatin sensitivity.

Results: In the present study, we found that the level of miR-223 was significantly positively correlated with cisplatin resistance. MiR-223 overexpression made NSCLC cells resistant to cisplatin treatment. We further found that autophagy mediated miR-223-mediated cisplatin resistance in NSCLC cells. Further mechanistic research demonstrated that miR-223 directly targeted FBXW7. The overexpression of miR-223 could inhibit the level of FBXW7 protein expression, thus promoting autophagy and making NSCLC cells resistant to cisplatin. Finally, we confirmed the increased effect of cisplatin sensitivity by miR-223 Antagomir in xenograft models of NSCLC.

Conclusions: Our results demonstrate that miR-223 could enhance autophagy by targeting FBXW7 in NSCLC cells. Inhibition of autophagy by miR-223 knockdown provides a novel treatment strategy to alleviate cisplatin resistance in NSCLC.

Keywords: MiR-223, Chemoresistance, Non-small cell lung cancer (NSCLC), Autophagy, FBXW7

*Correspondence: ckq3301@aliyun.com; wei_chen@zju.edu.cn

${ }^{\dagger}$ Hui Wang and Jiabin Chen contributed equally to this work

${ }^{2}$ Cancer Institute of Integrated Traditional Chinese and Western Medicine,

Zhejiang Academy of Traditional Chinese Medicine, Tongde Hospital

of Zhejiang Province, No.234, Gucui Road, Hangzhou 310012, Zhejiang, China

Full list of author information is available at the end of the article

\section{Background}

Although substantial effort has been paid to improving patient survival, lung cancer remains a leading cause of cancer-related mortality worldwide [1, 2]. Non-small cell lung cancer (NSCLC) accounted for approximately $80--85 \%$ of all lung cancer cases, with an overall 5 -year

(c) The Author(s) 2020. This article is licensed under a Creative Commons Attribution 4.0 International License, which permits use, sharing, adaptation, distribution and reproduction in any medium or format, as long as you give appropriate credit to the original author(s) and the source, provide a link to the Creative Commons licence, and indicate if changes were made. The images or other third party material in this article are included in the article's Creative Commons licence, unless indicated otherwise in a credit line to the material. If material is not included in the article's Creative Commons licence and your intended use is not permitted by statutory regulation or exceeds the permitted use, you will need to obtain permission directly from the copyright holder. To view a copy of this licence, visit http://creativeco mmons.org/licenses/by/4.0/. The Creative Commons Public Domain Dedication waiver (http://creativecommons.org/publicdomain/ zero/1.0/) applies to the data made available in this article, unless otherwise stated in a credit line to the data. 
survival rate of $<20 \%$ [3]. In addition, cisplatin-based traditional chemotherapy and molecular targeting drug therapy have greatly improved the prognosis and quality of life in NSCLC patients $[4,5]$. However, drug resistance is a vital bottleneck, which limits the effect of chemotherapy in most NSCLC patients [6, 7]. Therefore, elucidating the molecular mechanisms underlying drug resistance in NSCLC is critical.

MicroRNA (miRNA) is an endogenous non-coding RNA between 18 and 25 nucleotides, has been shown to regulate mRNA and protein expression by binding to the $3^{\prime}$-untranslated region (3'-UTR) of their target genes. Several previous studies on miRNA in NSCLC have been exerted and a series of miRNAs have been found to be involved in the development of NSCLC drug resistance $[8,9]$. Moreover, abnormal miR-223 expression has been detected in various cancers [10-15]. In NSCLC, previous studies described a controversial role of miR-223, functioning as either a tumor suppressor or an oncogene. In addition, Huang et al. reported that miR-223 may promote malignant phenotypes of lung cancer in A549 cells via activation of the NF- $\mathrm{KB}$ signaling pathway [16]. Liang et al. reported that platelet-secreted microvesicles (P-MVs) can promote lung cancer cell invasion via targeting the tumor suppressor, EPB41L3 [17]. In contrast, Zhou et al. reported that miR-223 inhibits tumor development of NSCLC and sensitizes A549 cells to gefitinib via targeting E2F1 [18]. Moreover, miR-223 was found to enhance the sensitivity of NSCLC cells to erlotinib by targeting the insulin-like growth factor-1 receptor [19]. However, another study showed that miR-223 could induce doxorubicin resistance through targeting F-box/ WD repeat-containing protein 7 (FBXW7)-mediated epithelial mesenchymal transition in NSCLC cells [20]. Thus, additional studies are essential to further uncover the role of miR-223 in the development and drug resistance in NSCLC.

Autophagy is vital biological process required for the maintenance of cellular biosynthesis, growth, and differentiation. Accumulating evidence has demonstrated that the abnormal activation of autophagy is an important factor involved in the process of chemoresistance [21, 22]. Moreover, recent studies indicate that miRNAs are frequently dysregulated in chemoresistant lung cancers, in which they have been shown to target autophagy-related genes or modulators. For example, miR-200b was shown to regulate autophagy associated with chemoresistance in human lung adenocarcinoma by targeting ATG12 [23]. In addition, the downregulation of miR-24-3p could induce etoposide (VP16)-cisplatin resistance in small-cell lung cancer by targeting ATG4A [24]. However, the relationship between miR-223 and autophagy in cancer remains poorly understood.
In the present study, we aimed to study the role of miR223 on cisplatin resistance in NSCLC and uncover the potential mechanisms. In the present study, we found that miR-223 could enhance cisplatin resistance in NSCLC by targeting FBXW7 and upregulating autophagy. Thus, we aimed to identify the pro-chemoresistant role of miR-223 in NSCLC cells in vitro.

\section{Materials and methods Cell lines and reagents}

Human NSCLC A549, NCI-H358, and NCI-H1299 cells were purchased from the ATCC (Manassas, VA, USA) and cultured in RPMI 1640 medium containing 10\% fetal bovine serum. PC9 was purchased from the Chinese Academy of Science Cell Bank (Shanghai, China) and cultured in DMEM medium containing 10\% fetal bovine serum. All cell lines were cultured at $37{ }^{\circ} \mathrm{C}$ in a humidified atmosphere $\left(95 \%\right.$ air and $\left.5 \% \mathrm{CO}_{2}\right)$. Cisplatin, rapamycin, and chloroquine were purchased from Sellerck (Huston, TX, USA).

\section{siRNA and transfection}

The miRNA mimics, miRNA inhibitors, and FBXW7 siRNA were synthesized by GenePharma (Shanghai, China). The sequences of primers were placed in Additional file 1: Table S1. Cells were transfected using Lipofectamine 3000 (Invitrogen, USA), according to the manufacturer's protocol.

\section{Cell viability assay}

Cells were seeded into 96 -well plates $\left(4 \times 10^{3}\right.$ cells/well $)$ directly or $24 \mathrm{~h}$ after transfection. After treatment with different concentrations of cisplatin combinations for $48 \mathrm{~h}$, cell viability was examined using a commercial CCK-8 kit (Dojindo, Kumamoto, Japan) according to the manufacturer's protocol, and the absorbance was determined at $450 \mathrm{~nm}$ using an MRX II microplate reader (Dynex, Chantilly, VA, USA).

\section{Western blot}

Cells were washed with PBS, harvested in ice-cold PBS, centrifuged at $2000 \mathrm{rpm}$ at $4{ }^{\circ} \mathrm{C}$, and lysed in RIPA buffer; protein concentrations were determined with a BCA kit (Pierce, Rockford, IL, USA). An equal amount of cell lysate for each condition was subjected to SDS-PAGE, transferred onto nitrocellulose members, and analyzed. The primary antibodies against FBXW7, LC3-I, LC3II, SQSTM1, and $\beta$-actin were purchased from Abcam (Cambridge, USA) and used at a concentration of 1:1000. The corresponding secondary antibody was also obtained from Abcam and used at a concentration of 1:5000. 
Real-time quantitative PCR (qRT-PCR)

Total RNA was extracted using Trizol (Takara, Japan) reagent. Reverse transcription and qRT-PCR were conducted using a SYBR Prime Script ${ }^{\text {TM }}$ miRNA RT-PCR kit (Takara, Japan,) according to the manufacturer's instructions. The level of miR-223 expression was normalized to U6 RNA. SYBR Premix Ex Taq (Takara, Japan) was also used to detect the level of FBXW7 mRNA. The sequences of primers were placed in Additional file 1: Table S1. Relative mRNA expression was normalized to $\beta$-actin. Data were analyzed using the $2 \Delta \Delta \mathrm{Ct}$ method.

\section{EdU assay}

Proliferation of the NSCLC cell lines was determined using a Click-iTEdU Imaging Kit (Invitrogen; Carlsbad, CA, USA) according to the manufacturer's protocol. Briefly, cells were treated with different conditions for $24 \mathrm{~h}$, and $10 \mu \mathrm{M}$ EdU was added for $2 \mathrm{~h}$ before fixation and permeabilization. Cell nuclei were stained with Hoechst 33342 (Invitrogen) at a concentration of $5 \mu \mathrm{g} /$ $\mathrm{mL}$ for $30 \mathrm{~min}$.

\section{Luciferase assays}

The 293T cells were co-transfected with wild-type or mutant FBXW7 $3^{\prime}$-UTR plasmid (Promega) as well as miR-223-3p mimics or miR-223-3p inhibitor (Ribo) using Lipofectamine 2000 (Invitrogen). Cell lysates were harvested $48 \mathrm{~h}$ after transfection and then firefly and Renilla luciferase activities were measured by a dual luciferase reporter assay kit according to the manufacturer's protocol. Renilla luciferase activity was used for normalization.

\section{Autophagic flux assay}

A549 and NCI-H1299 cells stably transfected with RFP-GFP-LC3 adenovirus were subjected to different treatments. After $48 \mathrm{~h}$, the cells were fixed with $4 \%$ paraformaldehyde (Sigma, USA) and photographed using a laser confocal fluorescence microscope. Cells were detected by the expression of green (GFP) or red (RFP) fluorescence. Autophagosomes were characterized by yellow puncta and autolysosomes based on only red puncta in the merged images. Autophagic flux was determined by an increased percentage of only red puncta in the merged images. A total of 300 cells were randomly selected to be counted and the number of autophagosomes and autolysosomes were averaged.

\section{Flow cytometry assay}

Cells were treated with cisplatin (IC50) for $48 \mathrm{~h}$. The cells were stained with the Annexin- $V$ and $7 \mathrm{AAD}$ according to the manufacturer's protocol. The rate of apoptosis was determined by flow cytometry.

\section{Immunohistochemistry and terminal uridine deoxynucleotidyl transferase dUTP nick-end labeling (TUNEL) assay}

The immunohistochemistry assay of Ki-67 was performed on $4 \mu \mathrm{m}$ of a thickness of paraffin-embedded mouse tissue sections. The sections were then incubated with the anti-Ki-67 antibody (1:500, Abcam) at $4{ }^{\circ} \mathrm{C}$ overnight. Then the primary antibodies were detected with an HRP-linked secondary antibody (Abcam) and developed using a 3'-diaminobenzidine substrate kit. The positively stained cells were defined as those with brown nuclei, and the percentage of positive tumor cells was determined. For apoptosis detection, apoptosis of the tumor tissues was determined with TUNEL assay using the In Situ Cell Death Detection Kit (Roche) according to the manufacturer's protocol. The apoptotic cells were observed under a light microscope.

\section{Tumor xenograft studies}

Animal experiments were conducted in compliance with the Guide for the Care and Use of Animal Ethics Committee of Zhejiang Chinese Medicine University (Hangzhou, China). $5 \times 10^{6}$ prepared A549 cells were injected subcutaneously into the right axillary fossa. Tumor length (L) and width (W) were measured and tumor volumes were calculated using the formula $\left(\mathrm{L} \times \mathrm{W}^{2}\right) / 2$. When tumor volumes reached $100 \mathrm{~mm}^{3}$, the mice were randomly divided into four groups $(\mathrm{n}=3)$, as followed: negative control, $5 \mathrm{mg} / \mathrm{kg}$ cisplatin, $8 \mathrm{nmol}$ antagomiR-223, or cisplatin combined with antagomiR-223. Cisplatin and antagomiR-223 were administered by intraperitoneal and intratumor injection, respectively, every 2 days for 2 weeks. All the mice were euthanized.

\section{Statistical analysis}

Data are presented as the mean \pm SD from three independent experiments and analyzed by a two-tailed Student's $t$-test using SPSS 18.0. Differences were considered significant at a value of $P<0.05$.

\section{Results}

The level of miR-223 was positively correlated with cisplatin resistance in NSCLC cells

To investigate the biological role of miR-223 in NSCLC cisplatin resistance, we first quantified the level of miR223 in four NSCLC cells. Our results revealed that the level of miR-223 was the highest in NCI-H1299 cells and lowest in PC-9 cells (PC-9< A549< NCI-H358< NCIH1299; Fig. 1a). Next we performed a CCK-8 assay to examine the viability of NSCLC cell lines exposed to 
cisplatin for $48 \mathrm{~h}$. Interestingly, the cell viability in each cell line represented an positive trend with the level of miR-223 (Fig. 1b); NSCLC cells with high miR-223 levels were more resistant to cisplatin. Moreover, miR-223 expression in cisplatin-treated NSCLC cells was significantly enhanced compared with control (Fig. 1c). Therefore, miR-223 expression may be involved in cisplatin resistance in NCSLC cells and could be induced in vitro during cisplatin therapy.

\section{MiR-223 regulates NSCLC cell sensitivity to cisplatin}

To further investigate the role of miR-223 on cisplatin resistance, NSCLC cells were transfected with a miR223 mimics, inhibitor or corresponding negative control (NC), respectively. And the effect on cellular viability was assessed followed by cisplatin treatment after transfection. As shown in Fig. 1d, transfection with the miR223 mimics gave rise to a marked decrease in cisplatin sensitivity in the NSCLC cells. In contrast, as shown in Fig. 1e, treatment with the miR-223 inhibitor resulted in a marked increase in cisplatin sensitivity. Transient miR223 transfection efficiency is presented in Fig. 1f. These results indicate that the forced expression of miR-223 promoted cisplatin resistance in NSCLC cells.

\section{Autophagy is involved in miR-223 mediated cisplatin resistance in NSCLC cells}

Since autophagy has been found to play a vital role in the development of chemoresistance in tumor cells [25], we hypothesized that miR-223 may help increase autophagy in NSCLC cells. To verify the hypothesis, we overexpressed miR-223 by transfecting NSCLC cells with the miR-223 mimics and then tested the autophagic flux using a tandem RFP-LC3-GFP construct. Our results demonstrated that both of the number of green-red (yellow) dots (representing autophagosomes) and the number of red-only dots (representing autolysosomes) were significantly increased following miR-223 overexpression, and the percentage of autolysosomes was increased, indicating enhanced autophagy (Fig. 2a, b).

We next explored whether autophagy is involved in miR-223-mediated cisplatin resistance. Firstly, we detected the role of cisplatin in regulating autophagy. A Western blot analysis showed that cisplatin treatment increased the level of LC3-I to LC3-II conversion and decreased the level of SQSTM1 expression, indicating enhanced autophagy (Additional file 2: Fig. S1). Secondly, we determined the level of autophagy in NSCLC cells treated with the miR-223 mimics compared to the negative control transfection following cisplatin co-treatment. We found that the cisplatin induced autophagy flux was enhanced by the miR-223 mimic, and the percentage of red-only dots indicative of autolysosomes significantly increased (Fig. 2c, d). In addition, we detected the cell apoptosis by flow cytometry assay. The results showed that miR-223 overexpression inhibited the cisplatininduced apoptosis (Additional file 3: Fig. S2).

Finally, a well-established autophagy inducer, rapamycin (RAPA), and autophagy blocker, chloroquine, were used to induce or inhibit autophagy, respectively. Chloroquine could enhance the sensitivity of NSCLC cells to cisplatin and increase SQSTM1 levels, a selective marker of autophagy while RAPA had the opposite effect (Additional file 4: Fig. S3). When NSCLC cells pretreated with CQ or RAPA were transfected with either the miR-223 mimics or negative miR-control, the cell viability results revealed that no matter autophagy was blocked or excessively induced, no significant difference was observed in CQ/RAPA group with or without miR-223 mimics (Fig. 3a, b). Consistent with the CCK-8 results, the Edu assay confirmed that the autophagy process was involved in miR-223-mediated cisplatin resistance in NSCLC cells (Fig. 3c-f). Taken together, these data indicate that miR223 may increase cisplatin resistance by up-regulating autophagy.

\section{FBXW7 is a direct target of miR-223}

To reveal the mechanism by which autophagy is enhanced by miR-223, we searched for potential target genes using targetscan, a bioinformatic database, and found that miR-223 was predicted to bind with $3^{\prime} \mathrm{UTR}$ regions of FBXW7 mRNA (Fig. 4a). Next we performed the luciferase activity to verify it, The results showed that the relative luciferase activity of the FBXW7-Wt plasmid was significantly suppressed after co-transfection with the miR-223-3p mimic. In contrast, this effect was not detected in the plasmid carrying the FBXW7-Mut (Fig. 4b). A qRT-PCR analysis found that the forced

(See figure on next page.)

Fig. 1 Forced miR-223 expression enhanced the cisplatin resistance of NSCLC cells. a Expression of miR-223 in NSCLC cell lines were detected by qRT-PCR. U6 was used as the internal reference. $\mathbf{b}$ Cell viability of NSCLC cell lines treated with different concentrations of cisplatin with a CCK-8 assay and IC50 value was calculated. c Expression of miR-223 in NSCLC cell lines were detected by qRT-PCR after cisplatin treatment. ${ }^{* *} P<0.01$;

${ }^{* * *} P<0.001$ compared with the control. $\mathbf{d}$, e NSCLC cells were transfected with an miR-223 mimic, miR-223 inhibitor, or the scrambled control. After $48 \mathrm{~h}$ post-transfection, different concentrations of cisplatin were added and cell viability was determined with a CCK-8 assay after $24 \mathrm{~h}$. ${ }^{* *} \mathrm{P}<0.01$ vs. the control. f Real-time PCR was used to validate the efficiency of the miR-223 inhibitor or miR-223 mimic. ${ }^{* *} P<0.01$; ${ }^{* *} P<0.001$ compared with the control 


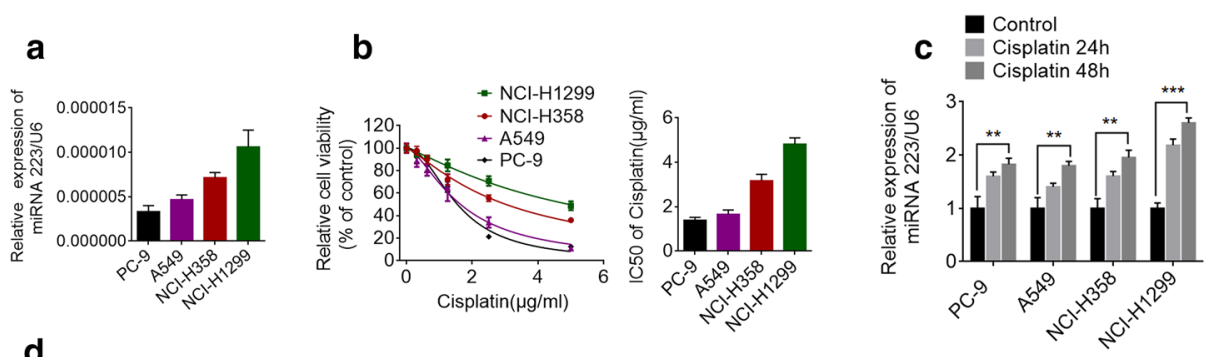

d
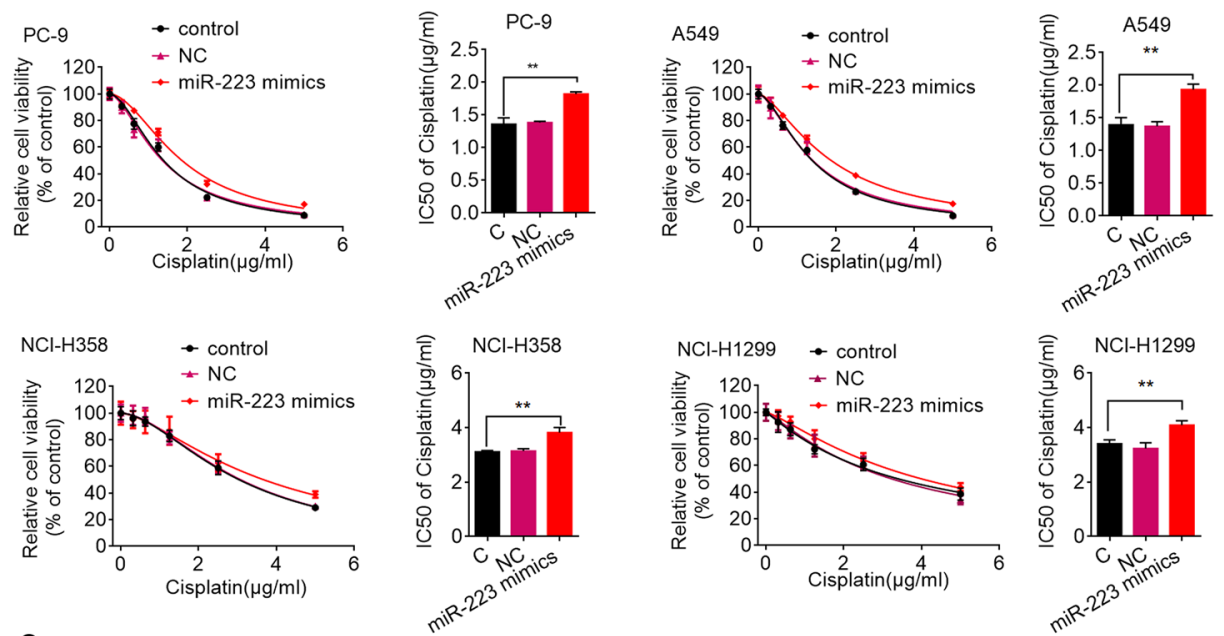

e
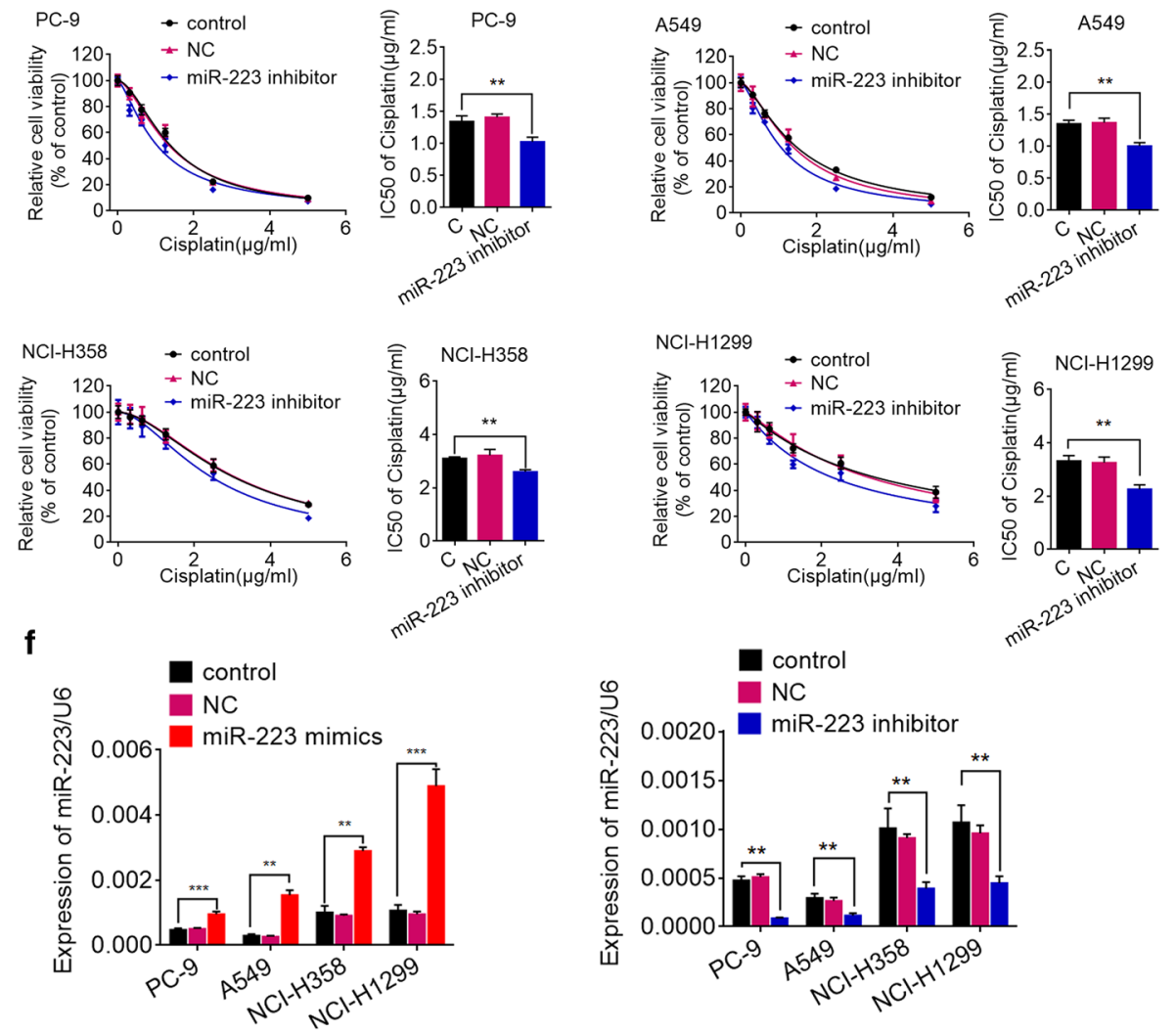
expression of miR-223 suppressed the level of FBXW7 mRNA in NSCLC cells. Conversely, the inhibition of miR-223 increased the level of FBXW7 mRNA (Fig. 4c). Moreover, Western blots showed that the overexpression of miR-223 inhibited the level of FBXW7 protein expression and miR-223 suppression up-regulated the level of FBXW7 protein (Fig. 4d). These results demonstrate that miR-223 directly targeted FBXW7 in NSCLC cells.

\section{MiR-223 increases autophagy and promotes cisplatin resistance by targeting FBXW7 in NSCLC cells}

Based on previous studies that suggested that FBXW7 regulates autophagy in several diseases and is a chemoresistance-related gene [26-28], we hypothesized that FBXW7 may mediate miR-223-induced enhanced autophagy and cisplatin resistance in NSCLC cells. To confirm this hypothesis, we first examined the level of FBXW7 mRNA and protein expression in NSCLC cells. Our results revealed that the level of FBXW7 expression level was inversely related to the level of miR-223 in NSCLC cells (Fig. 5a, Additional file 5: Fig. S4). Moreover, the knockdown of FBXW7 increased the resistance of NSCLC cells to cisplatin, which was consistent with the miR-223 overexpression findings (Fig. 5b, c). Next, the interfering efficiency of FBXW7 siRNA was determined (Fig. 5d). The cellular proliferation findings obtained from the Edu assay confirmed this result (Fig. 5e, f).

To further confirm that miR-223 exerts its influence primarily by directly targeting FBXW7, we employed rescue experiments by co-transfecting NSCLC cells with FBXW7 siRNA and the miR-223 inhibitor. We found that the miR-223-inhibition induced cytotoxic effects of cisplatin were eliminated by a knockdown of FBXW7 (Fig. 6a). The transfection efficiency is presented in Fig. 6b. The results from the Western blot analysis showed that the miR-223 knockdown led to the inhibition of autophagy, which was reversed by specific the FBXW7 siRNA (Fig. 6c, d). These results demonstrate that miR-223 directly targets FBXW7 to mediate cisplatin resistance and induce autophagy.

\section{MiR-223 inhibition enhances the efficacy of cisplatin for NSCLC in vivo}

To investigate the effects of miR-223 on cisplatin sensitivity, xenograft models were established via subcutaneous injection of A549 cells. The mice were treated with normal saline alone, cisplatin alone, miR-223 Antagomir alone, or cisplatin plus miR-223 Antagomir. Tumor growth was found no significant difference between the miR-223 Antagomir alone and the control group, while combined treatment led to significant inhibition of tumor growth compared with cisplatin alone (Fig. 7a, b). Ki-67 staining exhibited significantly decreased tumor cell proliferation rates in the cisplatin plus miR-223 Antagomir group compared to the cisplatin alone group (Fig. 7c, d); TUNEL assay showed highest tumor cell apoptosis in the cisplatin plus miR-223 Antagomir group (Fig. 7c, d). Taken together, these data confirmed that miR-223 inhibition enhances the efficacy of cisplatin for NSCLC in vivo.

\section{Discussion}

The cytotoxic-based platinum compound, cisplatin (cisplatin), has been commonly used as a first line treatment in NSCLC for decades. However, drug resistance to cisplatin in cancer cells remains a substantial challenge to a favorable prognosis [6]. The development of cisplatin resistance is a complex multifactorial process, involving reactive oxygen species (ROS), the aberrant expression of microRNAs, ATP-binding cassette (ABC) transporter effusion, and abnormal signaling pathways $[29,30]$. Accumulating evidence has demonstrated that autophagy is an essential pathway for cellular homeostasis and many studies have demonstrated that autophagy is involved in chemoresistance [31, 32]. Additionally, autophagy inhibitors have been explored as a means to sensitize chemoresistant cells to chemotherapy in clinical trials [33]. Recently, the regulation of autophagy by miRNAs has been shown to be a potentially effective strategy to reduce cancer cell chemoresistance [34]. Regarding NSCLC, while some studies have revealed a potential role of miRNAs and autophagy in cisplatin resistance in NSCLC [35, 36], no investigations have verified the ability of miR-223 and FBXW7 to directly impact the regulation of autophagy and cisplatin resistance in NSCLC cells. Therefore, additional studies are required to elucidate the relationship between miRNAs, autophagy, and cisplatin resistance in NSCLC. In the present study, we describe a novel mechanism by which miR-223 mediates cisplatin resistance by inhibiting FBXW7 to promote cisplatin-induced autophagy in NSCLC.

(See figure on next page.)

Fig. 2 MiR-223 overexpression promoted autophagy in NSCLC cells. a, b Autophagy flux was examined in A549 and NCl-H1299 cells transfected with the miR-223 mimics or miR-control using a tandem adenovirus RFP-GFP-LC3 construct. The number of autophagosomes (yellow dots) and autolysosomes (red-only dots) were assessed. ${ }^{*} P<0.05$ compared with Negative control. c, d Autophagy flux was examined in A549 and NCl-H1299 cells transfected with the miR-223 mimics or miR-control following treatment with the $\mathrm{IC}_{50}$ of cisplatin. The number of autophagosomes (yellow dots) and autolysosomes (red-only dots) were assessed. ${ }^{*} P<0.05$; ${ }^{* *} P<0.01$ compared with Negative control + cisplatin 
a
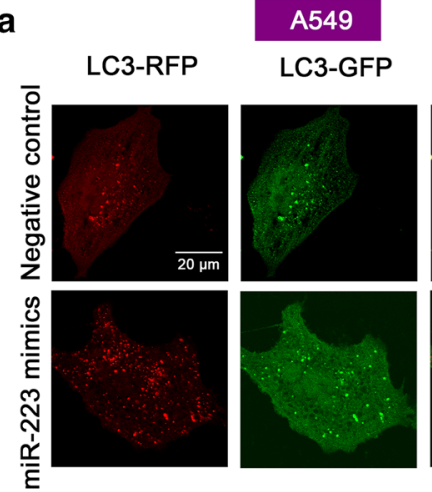

b

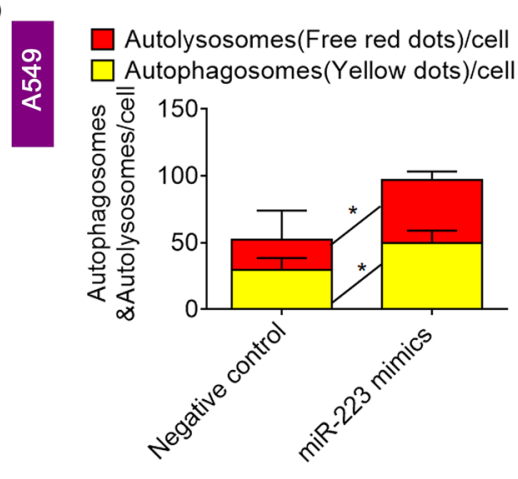

C

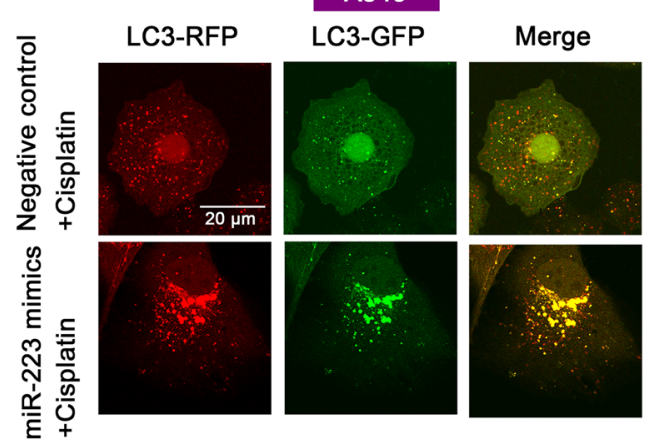

d

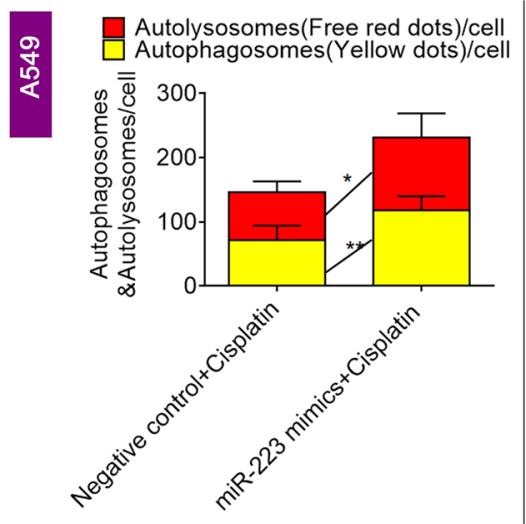

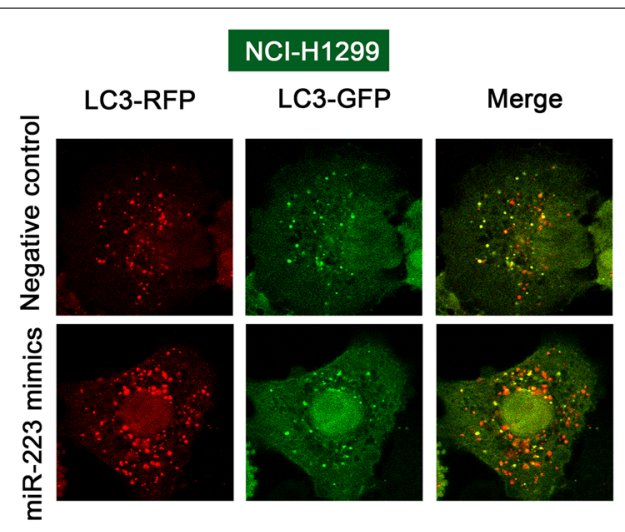
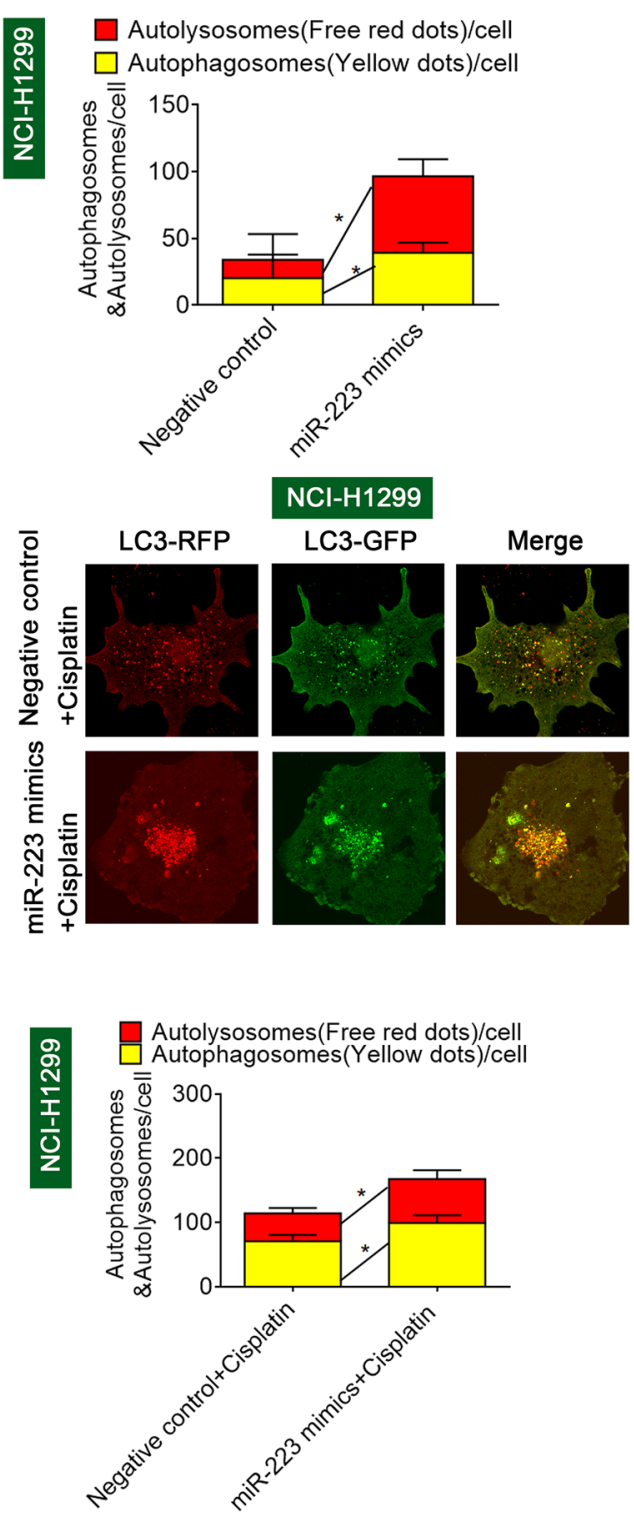


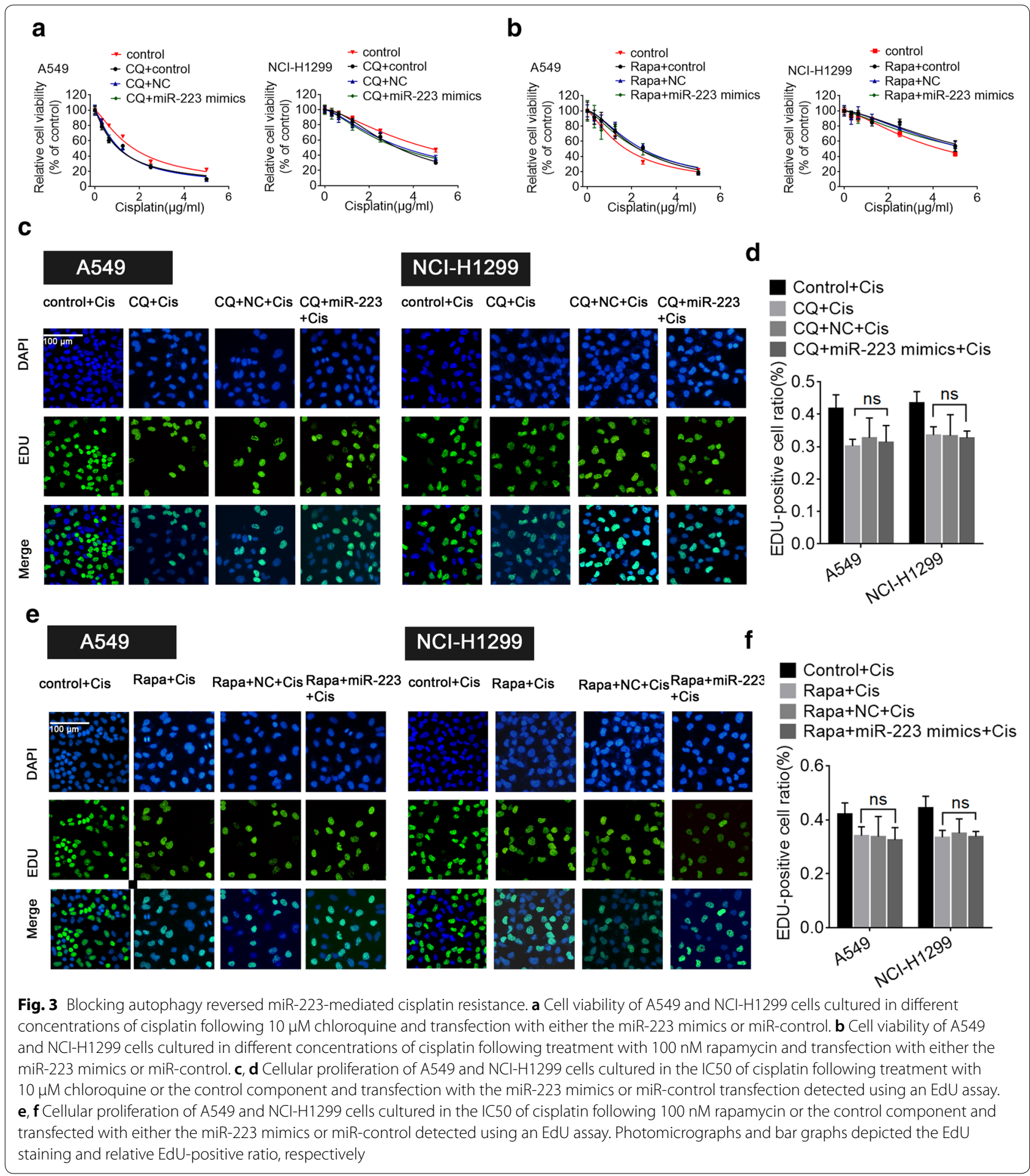

Increasing evidence has shown that miR-223 can function as either a cancer inducer or a tumor suppressor and is correlated with chemoresistance or chemosensitivity depending on the tumor type. In human gastric cancer, miR-223 was found to promote cisplatin resistance in human gastric cancer cells by regulating cell cycle 

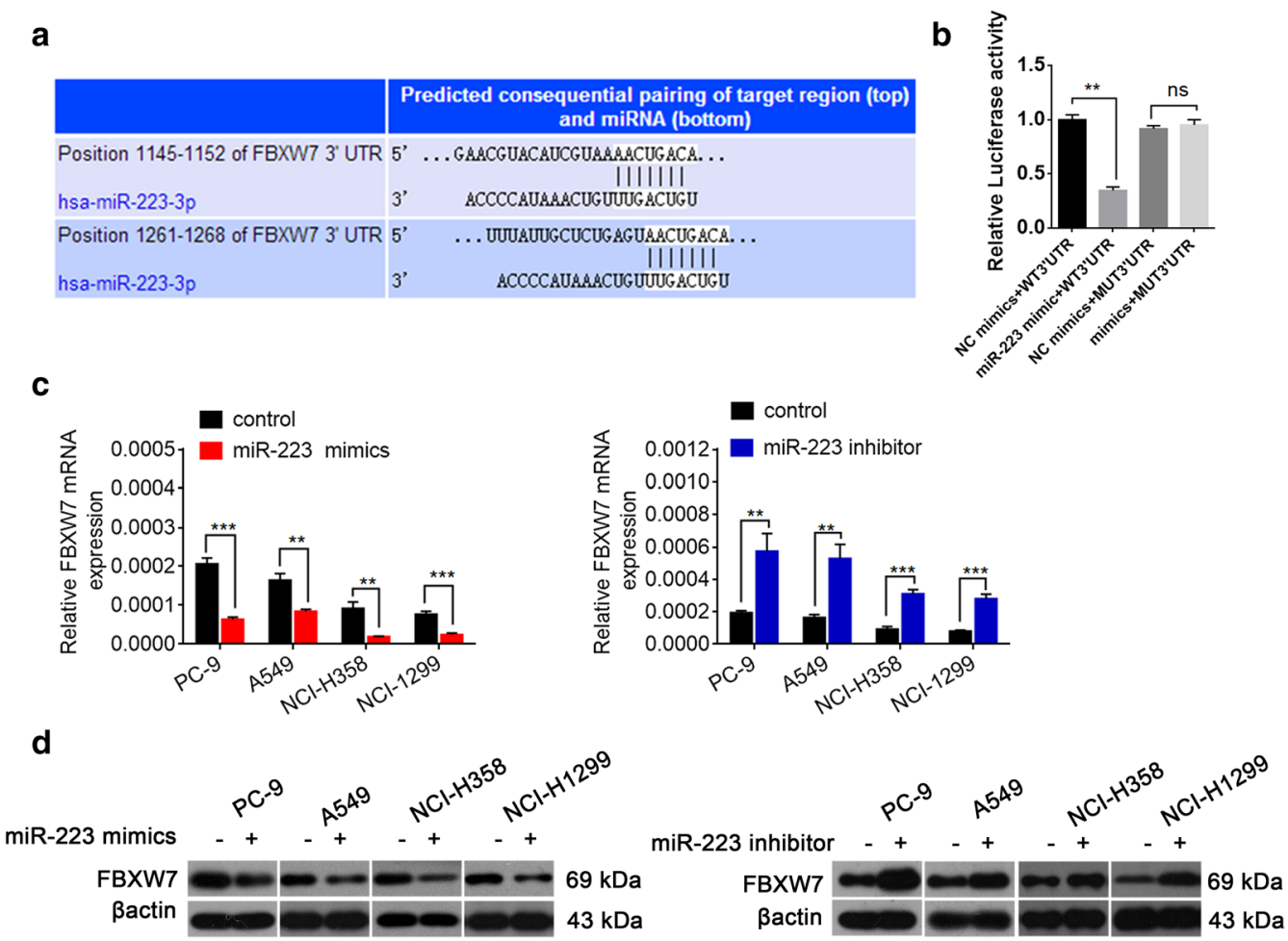

Fig. 4 miR-223 directly targets FBXW7 in NSCLC cells. a The predicted binding sequences of miR-223 in the $3^{\prime} U T R$ of FBXW7 by TargetScan. $\mathbf{b}$ miR-223-3p mimics suppressed the luciferase activity of the wild-type but not mutant of FBXW7 reporter in $293 T$ cells. ${ }^{* *} P<0.01$ compared with NC mimic +WT 3'UTR group. c Quantitative RT-PCR analyses of the effect of transient transfection with either the miR-223 mimic, miR-223 inhibitor, or negative control on the level of FBXW7 mRNA expression in NSCLC cells. ${ }^{* P}<0.05 ;{ }^{* *} P<0.01 ;{ }^{* * *}<0.001$ compared with control. $\mathbf{d}$ Quantification of FBXW7 protein expression in NSCLC cells transfected with either the miR-223 mimic, miR-223 inhibitor, or negative control by Western blot

through targeting FBXW7 [37]. In hepatocellular carcinoma, miR-223 was reported to modulate multidrug resistance via the downregulation of ABCB1 [38]. Moreover, in Glioblastoma, miR-223 was found to promote temozolomide chemoresistance in glioblastoma multiforme cells by targeting paired box 6 signaling [39]. However, the role of miR-223 on chemoresistance is inconsistent regarding NSCLC. Zhang et al. reported that increasing miR-223 expression could induce cell resistance to erlotinib in HCC827 cells [40]. In contrast, Han et al. reported that miR-223 could reverse the resistance of EGFR-TKIs through the IGF1R/PI3K/ Akt signaling pathway in NSCLC [41]. In addition, Zhou et al. reported that miR-223 could sensitize cancer cells to gefitinib by targeting E2F1 [18]. Therefore, additional studies are required to further elucidate the role of miR223 in NSCLC chemoresistance. In the present study, we showed that miR-223 can regulate cisplatin sensitivity in NSCLC by autophagy, indicating that miR223 may be mediate cisplatin resistance by autophagy. However, of these mechanisms of cisplatin resistance, the altered expression of MDR-related genes is the most common
[42, 43]. Maybe mir223-mediated cisplatin resistance is correlated with altered expression of MDR-related genes.

FBXW7, also known as FBW7, is a F-box-containing protein in the SCF E3 ligase complex, which functions in phosphorylation-dependent ubiquitination [44]. Moreover, FBXW7 has been identified as a tumor suppressor gene in several cancers and an FBXW7 knockdown was shown to sensitize cancer cells to chemotherapy $[26,45]$. Accumulation studies demonstrated that FBXW7 played a significant role in cancer cells by autophagy. For example, downregulated the expression of FBXW7 induced by high glucose activated mTOR signal, which led to diminished autophagy in renal mesangial cells [46]. Perifosine induces the degradation of key proteins in the mTOR axis through a GSK3/FBXW7-dependent mechanism in human lung cancer cells [47]. In addition, the relationship between miR-223 and FBXW7 has been studied in several cancers. In pancreatic ductal adenocarcinoma, miR-223 was reported to promote pancreatic cancer cell growth and invasion by targeting FBXW7 [48]. Moreover, the down-regulation of miR-223 could reverse the epithelial-mesenchymal transition (EMT) in gemcitabine-resistant pancreatic cancer cells [49]. In esophageal 


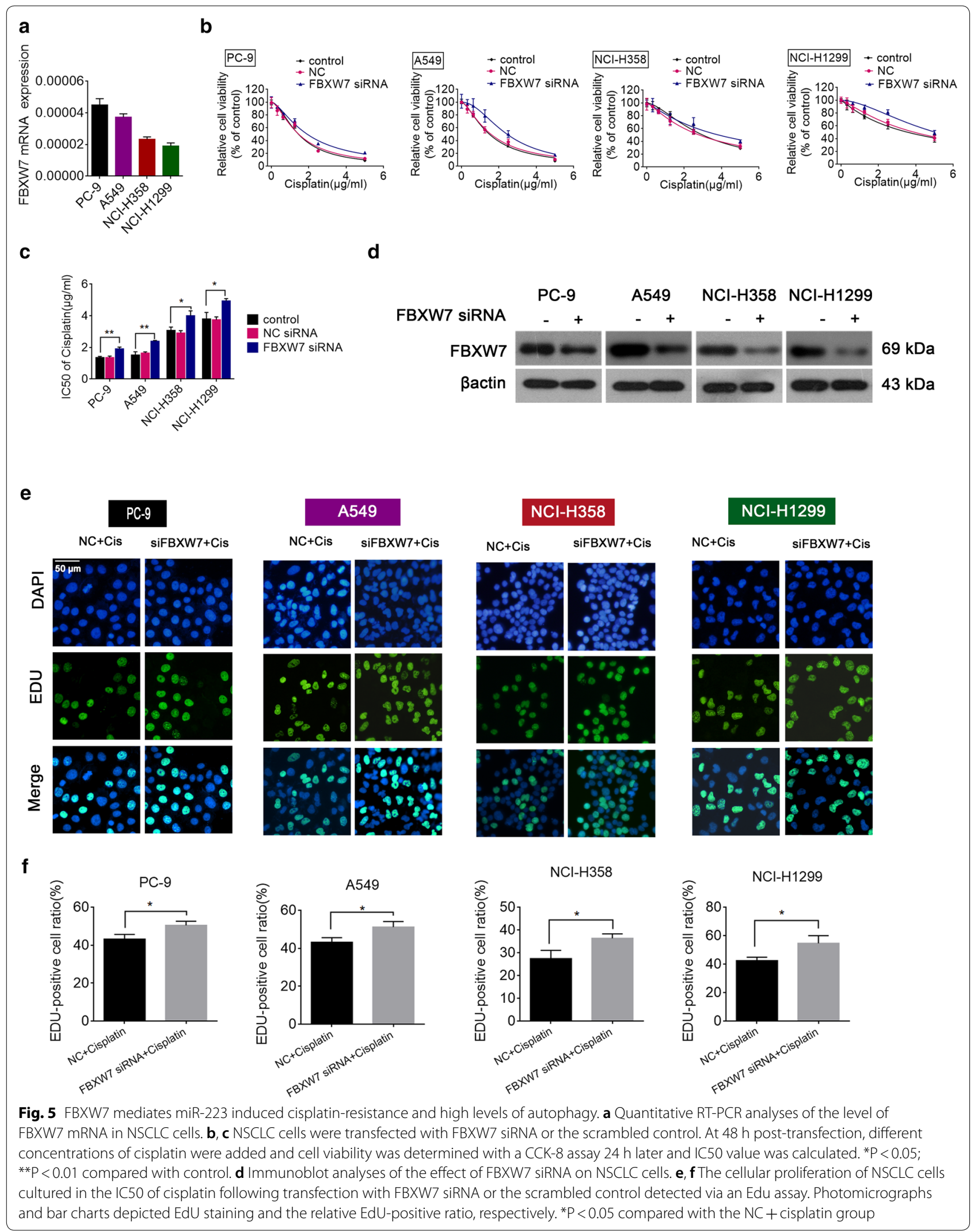




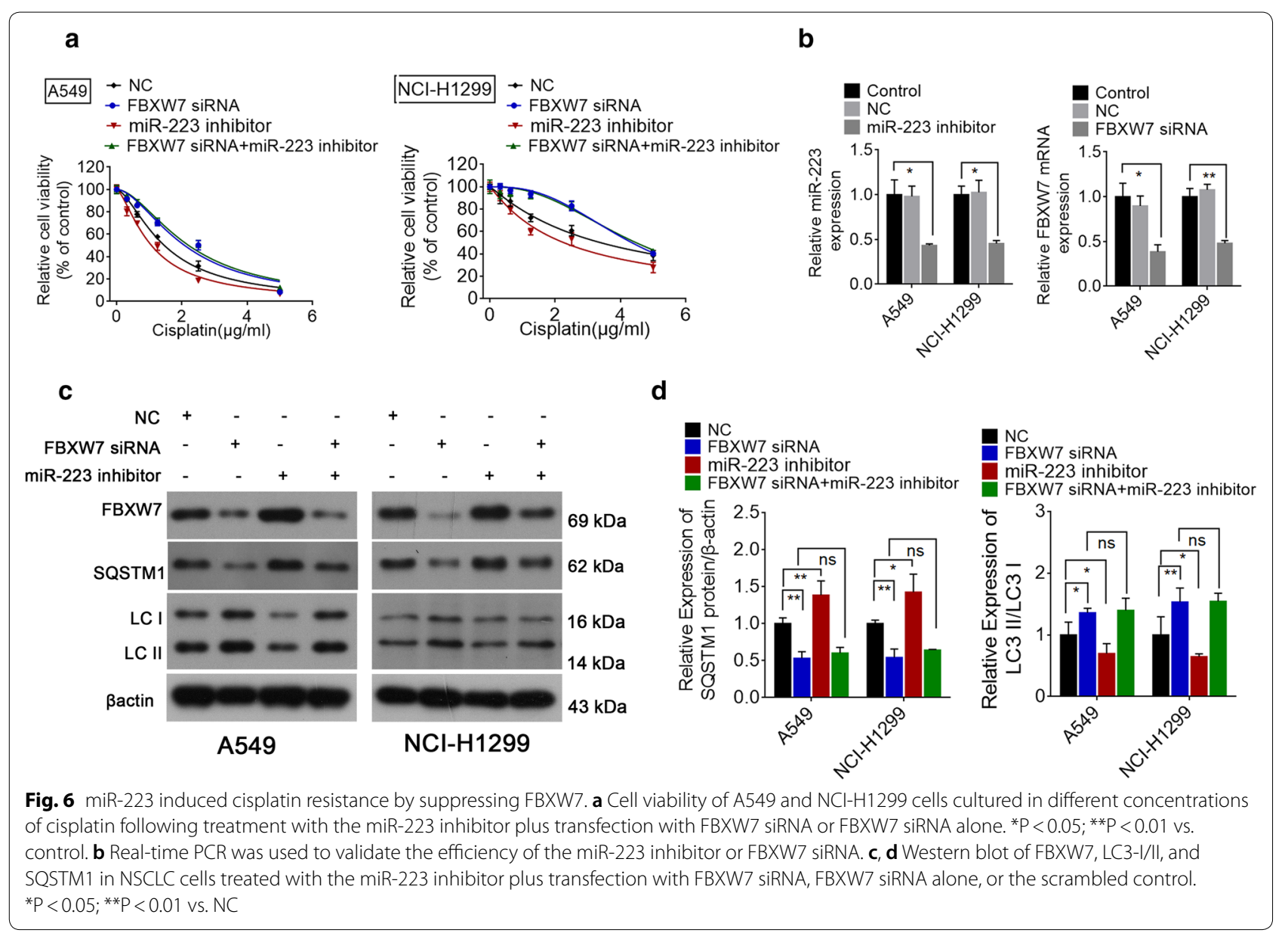

squamous cell carcinoma, the overexpression of miR-223 was found to promote tumor progression by inhibiting FBXW7-mediated regulation of the cell cycle [50]. In NSCLC, the miR-223/FBXW7 axis was reported to regulate doxorubicin sensitivity through EMT [20]. However, there are no existing reports on the miR-223/FBXW7 axis and the regulation of autophagy. In the present study, we have demonstrated for the first time that miR223 can induce autophagy and enhance cisplatin-induced autophagy by targeting FBXW7.

\section{Conclusion}

In conclusion, our findings indicate that miR-223 is a novel regulator of autophagy in NSCLC cells. Moreover, miR-223 was found to mediate autophagy by targeting FBXW7, which contributed to cisplatin resistance. Thus, the inhibition of autophagy by targeting miR-223FBXW7 axis might provide a useful strategy for overcoming drug resistance in NSCLC. 


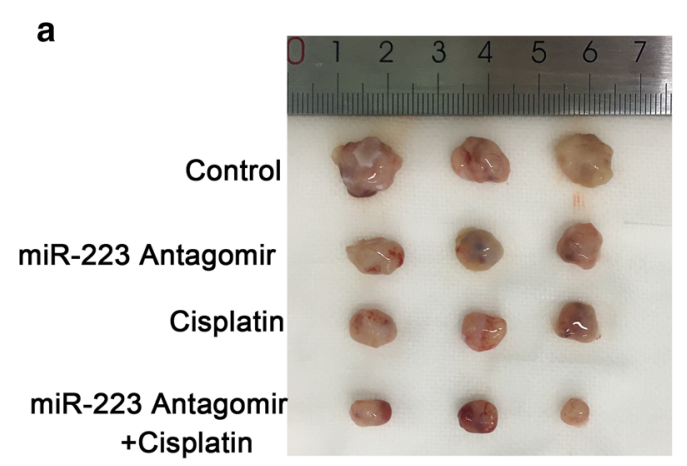

$$
\begin{aligned}
\text { b } \quad & \quad \text { - Control } \\
& \neq \text { miR-223 Antagomir } \\
& \quad \text { Cisplatin } \\
& =\text { miR-223 Antagomir+Cisplatin }
\end{aligned}
$$
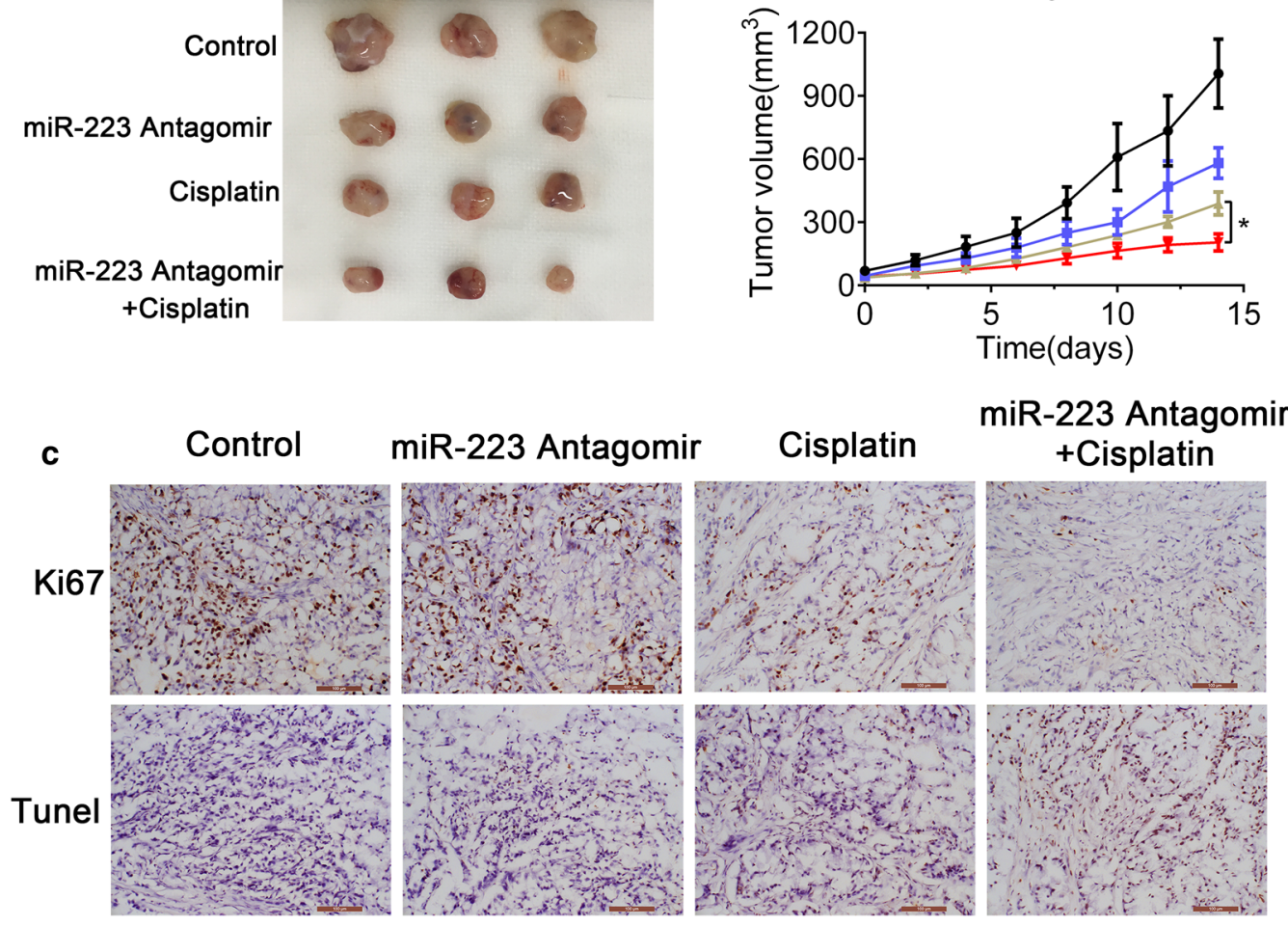

d
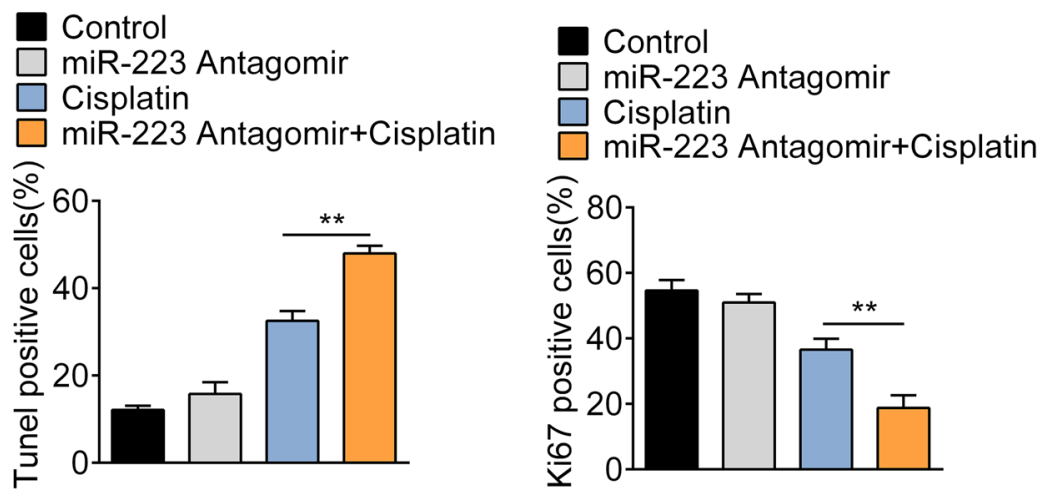

Fig. 7 MiR-223 inhibition enhances the efficacy of cisplatin for NSCLC in vivo. a Representative tumour images ( $n=3$ per group) were shown. The tumors were treated with control, cisplatin, miR-223 Antagomir, or cisplatin plus miR-223 Antagomir. b Growth curves of xenograft tumors treated with control, cisplatin, miR-223 Antagomir, or cisplatin plus miR-223 Antagomir. ${ }^{*} \mathrm{P}<0.05$ vs cisplatin. c, d Representative Ki-67 staining and TUNEL of apoptosis images in the treatment groups. ${ }^{* *} \mathrm{P}<0.01 \mathrm{vs}$. cisplatin 


\section{Supplementary information}

Supplementary information accompanies this paper at https://doi. org/10.1186/s12935-020-01284-x.

Additional file 1: Table S1. Sequences used for siRNA and RT-PCR in the study.

Additional file 2: Fig. S1. Effect of cisplatin on the expression of LC3-I/ II and SQSTM1 in NSCLC cells. (A) Western blot of LC3-I/II and SQSTM1 in NSCLC cells treated with the IC50 of cisplatin. (B) The relative expression of LC3-I/II and SQSTM1 protein was represented by calculating the grey value of the Western blot results. ${ }^{*} p<0.05,{ }^{* *} p<0.01$ and ${ }^{* * *} p<0.001$.

Additional file 3: Fig. S2. miR-223 overexpression inhibited apoptosis in NSCLC cells. (A) Flow cytometry assay was performed to detect cell apoptosis in A549 and NCl-H1299 cells subjected to different treatment. ${ }^{*} p<0.05,{ }^{* *} p<0.01$ vs. cisplatin.

Additional file 4: Figure S3. Effect of autophagy on cisplatin sensitivity and the expression of SQSTM1 in NSCLC cells. (A) NSCLC cells cultured in different concentrations of cisplatin were co-treated with $10 \mu \mathrm{M}$ chloroquine. After $24 \mathrm{~h}$, cell viability was determined using a CCK-8 assay. (B) NSCLC cells cultured in different concentrations of cisplatin were cotreated with $100 \mathrm{nM}$ rapamycin. After $24 \mathrm{~h}$, cell viability was determined using a CCK-8 assay. (C) Western blot of SQSTM1 in NSCLC cells treated with $10 \mu \mathrm{M}$ chloroquine or $100 \mathrm{nM}$ rapamycin.

Additional file 5: Figure S4. Western blot of FBXW7 in NSCLC cells.

\section{Abbreviations}

NSCLC: Non-small cell lung cancer; 3'-UTR: 3'-untranslated region; P-MVs: Platelet-secreted microvesicles; ROS: Reactive oxygen species; ABC: ATPbinding cassette; EMT: Epithelial-mesenchymal transition.

\section{Acknowledgements}

No application.

\section{Authors' contributions}

HW and CJ wrote the paper; SZ, XZ, SX and JM performed the experiments; $Y C, X L, L H$, and JS participated in the data collection and analysis; WC and KC conceived and designed the research. All authors read and approved the final manuscript.

\section{Funding}

This work was financially supported by Zhejiang Provincial Nature Science Foundation of China (LR2OH160001), Zhejiang Provincial Ten Thousand Plan for Young Top Talents (2018), Training objects of health innovative talents of Zhejiang Health (2018), Key Project Co-constructed by Zhejiang Province and Ministry (WKJ-ZJ-1916), Natural Science Foundation of China (81973767, 81972693, 81802383, 81972674, 81973654, 81673809 and 31900543), Zhejiang Provincial Traditional Chinese Medicine Science and Technology Project (2020ZZ004).

\section{Availability of data and materials}

All data generated or analyzed during this study are included in this published article.

\section{Ethics approval and consent to participate}

Not applicable.

\section{Consent for publication}

Not applicable.

\section{Competing interests}

The authors declare that they have no competing interests.

\section{Author details}

${ }^{1}$ Zhejiang Chinese Medical University, 548 Binwen Road, Binjiang District, Hangzhou 310053, Zhejiang, China. ${ }^{2}$ Cancer Institute of Integrated Traditional Chinese and Western Medicine, Zhejiang Academy of Traditional Chinese
Medicine, Tongde Hospital of Zhejiang Province, No.234, Gucui Road, Hangzhou 310012, Zhejiang, China.

Received: 26 August 2019 Accepted: 22 May 2020

Published online: 19 June 2020

\section{References}

1. Bray F, Ferlay J, Soerjomataram I, Siegel RL, Torre LA, Jemal A. Global cancer statistics 2018: GLOBOCAN estimates of incidence and mortality worldwide for 36 cancers in 185 countries. CA Cancer J Clin. 2018;68(6):394-424.

2. Siegel RL, Miller KD, Jemal A. Cancer statistics, 2019. CA Cancer J Clin. 2019;69(1):7-34.

3. Torre LA, Siegel RL, Jemal A. Lung cancer statistics. Adv Exp Med Biol. 2016;893:1-19.

4. Parums DV. Current status of targeted therapy in non-small cell lung cancer. Drugs Today. 2014;50(7):503-25.

5. Francis $\mathrm{H}$, Solomon B. The current status of targeted therapy for nonsmall cell lung cancer. Intern Med J. 2010;40(9):611-8.

6. Fennell DA, Summers Y, Cadranel J, Benepal T, Christoph DC, Lal R, et al. Cisplatin in the modern era: the backbone of first-line chemotherapy for non-small cell lung cancer. Cancer Treat Rev. 2016;44:42-50.

7. Sacco JJ, Al-Akhrass H, Wilson CM. Challenges and strategies in precision medicine for non-small-cell lung cancer. Curr Pharm Design. 2016;22(28):4374-85

8. Zhang YL, Yang Q, Wang SW. MicroRNAs: a new key in lung cancer. Cancer Chemoth Pharm. 2014;74(6):1105-11.

9. Feng B, Zhang K, Wang R, Chen LB. Non-small-cell lung cancer and miRNAs: novel biomarkers and promising tools for treatment. Clin Sci. 2015;128(10):619-34.

10. Arts FA, Keogh L, Smyth P, O'Toole S, Ta R, Gleeson N, et al. miR-223 potentially targets SWI/SNF complex protein SMARCD1 in atypical proliferative serous tumor and high-grade ovarian serous carcinoma. Hum Pathol. 2017;70:98-104.

11. Fassan M, Saraggi D, Balsamo L, Realdon S, Scarpa M, Castoro C, et al. Early miR-223 upregulation in gastroesophageal carcinogenesis. Am J Clin Pathol. 2017;147(3):301-8.

12. Laios A, O'Toole S, Flavin R, Martin C, Kelly L, Ring M, et al. Potential role of miR-9 and miR-223 in recurrent ovarian cancer. Mol Cancer. 2008;7:35.

13. Liu L, Zhang C, Li X, Sun W, Qin S, Qin L, et al. miR-223 promotes colon cancer by directly targeting p120 catenin. Oncotarget. 2017;8(38):63764-79.

14. Rodriguez-Vicente AE, Quwaider D, Benito R, Misiewicz-Krzeminska I, Hernandez-Sanchez M, de Coca AG, et al. MicroRNA-223 is a novel negative regulator of HSP90B1 in CLL. BMC Cancer. 2015;15:238.

15. Sun X, Li Y, Zheng M, Zuo W, Zheng W. MicroRNA-223 increases the sensitivity of triple-negative breast cancer stem cells to TRAIL-induced apoptosis by targeting HAX-1. PLOS ONE. 2016;11(9):e0162754.

16. Huang L, Li F, Deng P, Hu C. MicroRNA-223 promotes tumor progression in lung cancer A549 cells via activation of the NF-kappaB signaling pathway. Oncol Res. 2016;24(6):405-13.

17. Li XH, Zhang Y, Zhang HW, Liu XN, Gong TQ, Li MB, et al. miRNA-223 promotes gastric cancer invasion and metastasis by targeting tumor suppressor EPB41L3. Mol Cancer Res. 2011;9(7):824-33.

18. Zhou Z, Meng ZL, Hong YQ, Xiong YQ. miR-223 inhibits tumor development of non-small cell lung cancer and sensitizes cancer cells to gefitinib via targeting E2F1. Int J Clin Exp Pathol. 2017;10(3):2723-33.

19. Zhao FY, Han J, Chen XW, Wang J, Wang XD, Sun JG, et al. miR-223 enhances the sensitivity of non-small cell lung cancer cells to erlotinib by targeting the insulin-like growth factor-1 receptor. Int J Mol Med. 2016;38(1):183-91.

20. Li RY, Wu SJ, Chen X, Xu HF, Teng P, Li WD. miR-223/FBW7 axis regulates doxorubicin sensitivity through epithelial mesenchymal transition in nonsmall cell lung cancer. Am J Transl Res. 2016;8(6):2512.

21. Maes H, Rubio N, Garg AD, Agostinis P. Autophagy: shaping the tumor microenvironment and therapeutic response. Trends Mol Med. 2013;19(7):428-46. 
22. Sannigrahi MK, Singh V, Sharma R, Panda NK, Khullar M. Role of autophagy in head and neck cancer and therapeutic resistance. Oral Dis. 2015;21(3):283-91.

23. Pan B, Feng B, Chen $Y$, Huang G, Wang R, Chen L, et al. MiR-200b regulates autophagy associated with chemoresistance in human lung adenocarcinoma. Oncotarget. 2015;6(32):32805-20.

24. Pan B, Chen Y, Song H, Xu Y, Wang R, Chen L. Mir-24-3p downregulation contributes to VP16-DDP resistance in small-cell lung cancer by targeting ATG4A. Oncotarget. 2015;6(1):317-31.

25. Huang Z, Zhou L, Chen ZB, Nice EC, Huang CH. Stress management by autophagy: implications for chemoresistance. Int J Cancer. 2016;139(1):23-32.

26. Ishii N, Araki K, Yokobori T, Gantumur D, Yamanaka T, Altan B, et al. Reduced FBXW7 expression in pancreatic cancer correlates with poor prognosis and chemotherapeutic resistance via accumulation of MCL1. Oncotarget. 2017;8(68):112636-46.

27. Ahn JS, Ann EJ, Kim MY, Yoon JH, Lee HJ, Jo EH, et al. Autophagy negatively regulates tumor cell proliferation through phosphorylation dependent degradation of the Notch 1 intracellular domain. Oncotarget. 2016:7(48):79047-63.

28. Xu Y, Tian C, Sun J, Zhang J, Ren K, Fan XY, et al. FBXW7-induced MTOR degradation forces autophagy to counteract persistent prion infection. Mol Neurobiol. 2016;53(1):706-19.

29. Zang HJ, Peng JL, Wang WY, Fan SQ. Roles of microRNAs in the resistance to platinum based chemotherapy in the non-small cell lung cancer. J Cancer. 2017:8(18):3856-61.

30. Chang A. Chemotherapy, chemoresistance and the changing treatment landscape for NSCLC. Lung Cancer. 2011;71(1):3-10.

31. Cui JZ, Gong ZY, Shen HM. The role of autophagy in liver cancer: molecular mechanisms and potential therapeutic targets. Bba-Rev Cancer. 2013;1836(1):15-26.

32. Islam MA, Sooro MA, Zhang P. Autophagic Regulation of p62 is Critical for Cancer Therapy. Int J Mol Sci. 2018;19(5).

33. Rangwala R, Chang YYC, Hu J, Algazy K, Evans T, Fecher L, et al. Combined MTOR and autophagy inhibition Phase I trial of hydroxychloroquine and temsirolimus in patients with advanced solid tumors and melanoma. Autophagy. 2014;10(8):1391-402.

34. Chen LX, Zhou YX, Sun QH, Zhou JC, Pan HM, Sui XB. Regulation of autophagy by MiRNAs and their emerging roles in tumorigenesis and cancer treatment. Int Rev Cell Mol Biol. 2017;334:1-26.

35. Hua L, Zhu G, Wei J. MicroRNA-1 overexpression increases chemosensitivity of non-small cell lung cancer cells by inhibiting autophagy related 3-mediated autophagy. Cell Biol Int. 2018;42(9):1240-9.

36. Liu JG, Xing YR, Rong L. miR-181 regulates cisplatin-resistant non-small cell lung cancer via downregulation of autophagy through the PTEN/ PI3K/AKT pathway. Oncol Rep. 2018;39(4):1631-9.

37. Zhou X, Jin W, Jia H, Yan J, Zhang G. MiR-223 promotes the cisplatin resistance of human gastric cancer cells via regulating cell cycle by targeting FBXW7. J Exp Clin Cancer Res. 2015;34:28.
38. Yang T, Zheng ZM, Li XN, Li ZF, Wang Y, Geng YF, et al. MiR-223 modulates multidrug resistance via downregulation of $A B C B 1$ in hepatocellular carcinoma cells. Exp Biol Med. 2013;238(9):1024-32.

39. Cheng Q, Ma XQ, Cao H, Chen ZG, Wan X, Chen R, et al. Role of miR-223/ paired box 6 signaling in temozolomide chemoresistance in glioblastoma multiforme cells. Mol Med Rep. 2017;15(2):597-604.

40. Zhang H, Chen F, He Y, Yi L, Ge C, Shi X, et al. Sensitivity of non-small cell lung cancer to erlotinib is regulated by the Notch/miR-223/FBXW7 pathway. Biosci Rep. 2017;37(3).

41. Han J, Zhao FY, Zhang J, Zhu HZ, Ma H, Li XT, et al. miR-223 reverses the resistance of EGFR-TKIs through IGF1R/PI3K/Akt signaling pathway. Int J Oncol. 2016;48(5):1855-67.

42. Lu C, Shan Z, Li C, Yang L. MiR-129 regulates cisplatin-resistance in human gastric cancer cells by targeting P-gp. Biomed Pharmacother. 2017;86:450-6.

43. Yamagishi T, Sahni S, Sharp DM, Arvind A, Jansson PJ, Richardson DR. P-glycoprotein mediates drug resistance via a novel mechanism involving lysosomal sequestration. J Biol Chem. 2013;288(44):31761-71.

44. Koepp DM, Schaefer LK, Ye X, Keyomarsi K, Chu C, Harper JW, et al. Phosphorylation-dependent ubiquitination of cyclin E by the SCFFbw7 ubiquitin ligase. Science. 2001;294(5540):173-7.

45. Lin J, Ji AH, Qiu GZ, Feng HZ, Li J, Li S, et al. FBW7 is associated with prognosis, inhibits malignancies and enhances temozolomide sensitivity in glioblastoma cells. Cancer Sci. 2018;109(4):1001-11.

46. Gao C, Fan F, Chen J, Long Y, Tang S, Jiang C, et al. FBW7 regulates the autophagy signal in mesangial cells induced by high glucose. Biomed Res Int. 2019;2019:6061594.

47. Fu L, Kim YA, Wang X, Wu X, Yue P, Lonial S, et al. Perifosine inhibits mammalian target of rapamycin signaling through facilitating degradation of major components in the mTOR axis and induces autophagy. Cancer Res. 2009;69(23):8967-76.

48. He D, Huang C, Zhou QX, Liu DW, Xiong LH, Xiang HX, et al. HnRNPK/miR223/FBXW7 feedback cascade promotes pancreatic cancer cell growth and invasion. Oncotarget. 2017;8(12):20165-78.

49. Ma J, Fang BB, Zeng FP, Ma C, Pang HJ, Cheng L, et al. Down-regulation of miR-223 reverses epithelial-mesenchymal transition in gemcitabineresistant pancreatic cancer cells. Oncotarget. 2015;6(3):1740-9.

50. Kurashige J, Watanabe M, Iwatsuki M, Kinoshita K, Saito S, Hiyoshi Y, et al. Overexpression of microRNA-223 regulates the ubiquitin ligase FBXW7 in oesophageal squamous cell carcinoma. Br J Cancer. 2012;106(1):182-8.

\section{Publisher's Note}

Springer Nature remains neutral with regard to jurisdictional claims in published maps and institutional affiliations.

Ready to submit your research? Choose BMC and benefit from

- fast, convenient online submission

- thorough peer review by experienced researchers in your field

- rapid publication on acceptance

- support for research data, including large and complex data types

- gold Open Access which fosters wider collaboration and increased citations

- maximum visibility for your research: over 100M website views per year

At BMC, research is always in progress.

Learn more biomedcentral.com/submissions 